\title{
Task Force Report 5. Report of the Task Force on Family Medicine's Role in Shaping the Future Health Care Delivery System
}

\author{
Richard G. Roberts, MD, JD \\ Pam S. Snape, $M D^{2}$ \\ Kevin Burke ${ }^{3}$ \\ ${ }^{1}$ Chair, Task Force Report 5, Madison, Wisc \\ ${ }^{2}$ Vice Chair, Task Force Report 5, Greenville, SC \\ ${ }^{3}$ Staff Executive, Task Force Report 5, \\ Washington, DC
}

Conflicts of interest: none reported

\section{CORRESPONDING AUTHOR}

Kevin Burke

2021 Massachusetts Avenue, NW

Washington, DC 20036

kburke@aafp.org

\begin{abstract}
BACKGROUND Recognizing that the implementation of needed changes within family medicine will be enhanced through a concurrent effort to transform the broader health care system, this Future of Family Medicine task force was charged with determining family medicine's leadership role in shaping the future health care delivery system.
\end{abstract}

METHODS After reviewing the changes taking place within family medicine and the broader health care system, this task force identified 6 priorities for fostering necessary modifications in the health care system. In addressing the leadership challenge facing the discipline, the task force presents a 3-dimensional matrix that provides a useful framework for describing the audiences that should be targeted, the strategic priorities that should be pursued, and the specific recommendations that should be addressed. Noting that leadership is part of the heritage of family medicine, the task force reviewed past successes by the discipline as important lessons that can be instructive as family physicians begin advocating for needed changes.

MAJOR FINDINGS Effective leadership is an essential ingredient that will determine, to a large extent, the success of family medicine in advocating for needed change in the health care system overall and in the specialty. It is vitally important to groom leaders within family medicine and to create venues where policy makers and influence leaders can look beyond their usual constituencies and horizons to a comprehensive view of health care. A central concept being proposed is that of a relationship-centered personal medical home. This medical home serves as the focal point through which all individuals-regardless of age, gender, race, ethnicity, or socioeconomic status - receive a basket of acute, chronic, and preventive medical care services that are accessible, accountable, comprehensive, integrated, patient-centered, safe, scientifically valid, and satisfying to both patients and their physicians.

CONCLUSION Family medicine has and will continue to have an important leadership role in health system change. It has been most successful when it has been able to identify a high-priority goal through consensus within the discipline, to focus and coordinate local and national resources, and to use a multipronged approach in addressing the priority. Although the Future of Family Medicine project has provided an important impetus for the identification of key priorities across the discipline, for the FFM project ultimately to be a success, implementation steps will need to be identified and prioritized. The leadership matrix presented in this report can provide a useful structuring tool to identify, understand, and coordinate change efforts more effectively. Strategic alliances with primary care groups and others also will be critical to the success of change initiatives.

Ann Fam Med 2004;2:S88-S99. DOI: 10.1370/afm.138.

TASK FORCE CHARGE: Determine family medicine's leadership role in shaping the future health care delivery system. 


\section{INTRODUCTION}

"Good doctors must practise in a good system."

George Bernard Shaw ${ }^{1}$

$\mathrm{I}$ is hard to do well in a sick health care system. This statement holds true for both patients and physicians. Americans are frustrated by a health care system that produces wondrous results for a few, but costs so much that even basic care is increasingly unaffordable for many; that promises the latest in science and technology, but delivers fragmented, impersonal, or inconsistent high-quality care; that experiments eagerly with new models for financing and delivering care, but acknowledges reluctantly the resulting chaos and inequities that follow.

Nearly 4 decades ago, the specialty of family practice was created to train physicians to go where they were needed and provide the care their communities sought. To a considerable degree, the specialty has fulfilled its promise. ${ }^{2}$ Yet, the trends that threaten US health care today are similar to the concerns that gave rise to the creation of the specialty of family medicine-escalating costs, excess specialization, inappropriate use of technology, depersonalized care, uneven quality, and inequality of access.

The failure to remedy these concerns has less to do with family practice and more to do with the reluctance of the United States to commit to explicit and shared goals for its health care system. Eight US presidents, from Teddy Roosevelt to Bill Clinton, have tried without success to rally Americans around a comprehensive health care reform agenda. Several recent Institute of Medicine (IOM) reports have detailed the current system's failings, including Crossing the Quality Chasm: A New Health System for the 21st Century, which recommended the following 6 aims for an improved system: that care be safe, timely, effective, equitable, patient-centered, and efficient. ${ }^{3}$ The task force offers this report as an expression of the belief that the time has come for those who provide most of the medical care to most Americans-family physicians and other primary care clinicians - to exert leadership, engage Americans in a dialogue about their health care, and articulate a compelling vision for a better US health care system that achieves the 6 IOM aims.

The US health care system can be transformed to serve its people better by focusing on 6 strategic priorities that will lead to the achievement of the 6 aims. Several of the priorities depend primarily on the efforts of family medicine alone, which is not surprising given that the Future of Family Medicine (FFM) project is an initiative of and by the discipline of family medicine. The primary objective of the FFM project is to change the discipline of family medicine to better meet the needs of the people. Family physicians are relying on the FFM project to identify strategic directions that resonate across the discipline and to offer specific recommendations to help improve family physicians' performance. In doing so, the discipline can lead others by example.

At the same time, family medicine cannot succeed, nor will the needs of the public be met, without fundamental changes in the US health care system. Thus, other priorities will require collaboration with other groups, especially other primary care clinicians, because the primary care specialties have more in common than not. Still other priorities will involve reaching out to multiple, larger audiences. While some of family medicine's priorities and recommendations are more narrow and targeted than others, they are all intended to heal an ailing US health care system by stimulating a national conversation and fostering actions that change how Americans think about and use their health care system.

The Task Force recommends that family medicine pursue the following 6 priorities as a means of fostering necessary changes in the health care system:

1. Asserting leadership to transform the US health care system by initiating a dialogue on how best to provide integrated care of the whole person

2. Taking steps to ensure that every American has a personal medical home

3. Promoting the use and reporting of quality measures to improve performance and service

4. Advocating that every American have health care coverage for basic services and protection against extraordinary health care costs

5. Developing reimbursement models to sustain family medicine and primary care

6. Advancing research that supports the clinical decision making of family physicians and other primary care clinicians

\section{PRIORITY 1: ASSERT LEADERSHIP TO TRANSFORM THE AMERICAN HEALTH CARE SYSTEM}

\section{Leading Health System Change: Who to What, How?}

The following leadership question is the most succinct summary of the charge to this task force: "Leading health system change: who to what, how?" These 3 foci (who, what, how) make for a helpful 3-dimensional matrix (Figure 1) and provide a useful framework for describing which audiences (who) should be targeted to achieve the strategic priorities (what) through specific recommendations (how) 


\section{Figure 1. The leadership matrix.}

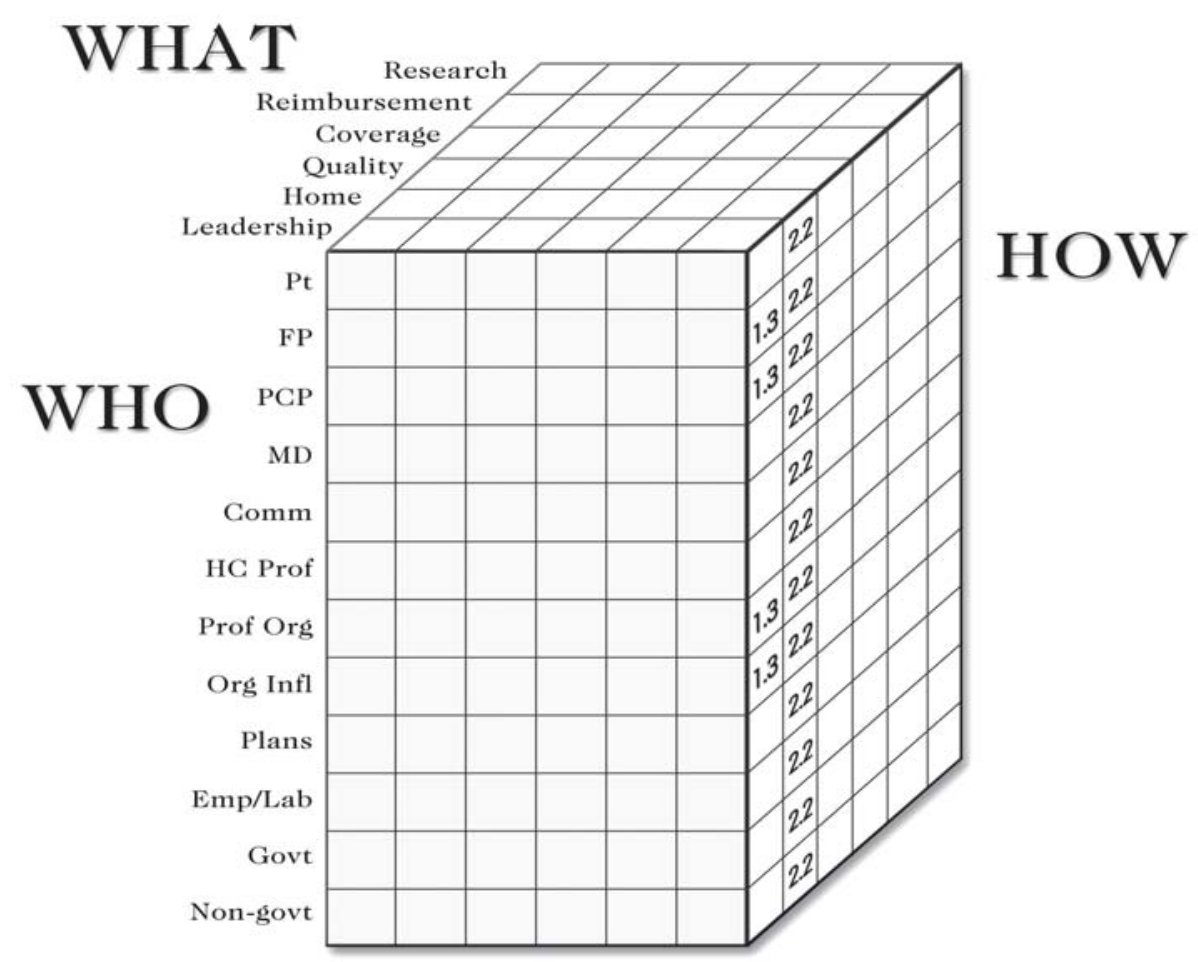

$\mathrm{Pt}=$ patients; FP = family physicians; PCP = primary care physicians; Comm = local communities; HC Prof $=$ health care professionals; Prof Org $=$ professional organizations; Org Infl = change agents and organizations of influence; Plans = health plans; Emp/Lab = employers and labor organizations; Govt = government policy makers;

Non-govt $=$ nongovernmental policy makers.

Those identified as "who" comprise the various audiences for leadership efforts. At times, these audiences represent potential allies; at other times, potential adversaries. The "what" signifies the key elements, or strategic priorities, to achieve the compelling vision for US health care. The "how" indicates specific recommendations to accomplish the agreed-upon priorities.

As an example of how the leadership matrix applies to a given issue, one task force recommendation (recommendation 1.3), which is discussed below, is that a leadership center for family medicine and primary care be created (what). This recommendation involves a select few audiences (who). One audience, family physicians and primary care physicians, would be encouraged to support and contribute to the creation of such a center (how). Other likely audiences, such as the professional organizations of primary care physicians, would provide start-up funds and staff support to get the center up and running (another how). Still other audiences, such as foundations, would grant funds to help offset the cost of establishing the center (yet another how). There are successful examples that provide useful insights for leadership development initiatives, such as the Society of Teachers of Family Medicine (STFM) F. Marian Bishop Fellowship for academic family physicians.
Another recommendation (recommendation 2.2) of this task force, presented below, advocates for an information campaign on the value of a personal medical home. This example contemplates a much wider range of audiences. For instance, if the "who" are patients, and the "what" is a personal medical home; then an example of a "how" would be to ensure that every unassigned patient who visits an emergency department (ie, someone without an identified personal physician) receives an explanation of the importance of a medical home/ relationship with a personal physician and a list of available medical homes/physicians in the area. Other tactics to promote the concept of a personal medical home to patients include public service announcements and celebrity testimonials on the importance of having a medical home.

Using the leadership matrix, it becomes apparent that the successful implementation of the medical home recommendation could easily involve a different tactic (how) for each of the 12 target audiences. For example, all health care professionals would be encouraged to reinforce the importance of the medical home at every patient contact; they would be encouraged to do so through research findings and communications showing the value of a medical home. Communities would 
be urged to embark on outreach efforts to make certain that all their residents had medical homes. Professional organizations and organizations of influence would be enlisted to educate their members and trainees about the value of a medical home. Health plans, employers, labor unions, and government would promote and provide incentives for using a medical home. Accreditation organizations would measure the level and accredit based on the usage of the medical home, much as is done currently by the National Committee for Quality Assurance (NCQA).

\section{Target Audiences (Who)}

There are numerous key audiences when it comes to changing the US health care system. While it is possible to list every person or organization that might be a potential ally or foe, there are 12 audiences that are most important for the types of leadership endeavors and policy initiatives most likely to be undertaken by family medicine. The specific audience of interest will depend on the strategic priority under consideration and its related recommendations for action.

\section{Patients}

Data from around the world have shown that a continuing relationship between patient and physician is an essential component of the most successful health systems with the best outcomes. ${ }^{4}$ Physicians have been reluctant to enlist patients in larger social issues, such as health care reform, but their awareness and support are crucial if positive change is to occur.

\section{Family Physicians}

Major initiatives by family medicine must first pass the reality check of practicing family physicians. Without their support, such efforts are likely to be misdirected and to fail.

\section{Primary Care Physicians}

Family physicians have much in common with other primary care physicians (ie, general internists and general pediatricians). Whereas there are important differences between the respective primary care disciplines, success is much more likely when other primary care groups are recruited to the cause. Other physician groups look to family medicine as the natural leader on primary care issues. This leadership is a responsibility family medicine should embrace.

\section{Other Physicians}

Although physicians in other specialties may fear that they have much to lose in a reformed system that better supports primary care, they are also frustrated with the current system, which is expensive, fragmented, and under-performing. Common ground can be found most often when efforts center on the welfare of patients rather than on financial self-interest.

\section{Local Communities}

The FFM research ${ }^{5}$ identified the contributions of family physicians to their communities as the "best kept secret" of the discipline. Communities are powerful potential allies and a largely untapped resource that should be mobilized on behalf of their local primary care clinicians and the community's health.

\section{Health Care Professionals}

Many nurses, physician assistants, various types of therapists, public health workers, and other health care professionals share a desire for a reformed health care system. Family physician anxieties about being replaced by nonphysicians have not borne out; everyone in primary care has more than enough to do. Such fears reflected an incomplete and inaccurate understanding of the comprehensive care provided in the primary care setting, the importance of teams to address more effectively the increasingly complex needs of patients, and the valuable contributions offered by the various members of the primary health care team.

\section{Professional Organizations}

Associations such as the American Medical Association (AMA), the American College of Physicians, the American Academy of Pediatrics, the American Academy of Physician Assistants, the American Nurses Association, and others can be important partners for health care reform. While each organization will have a different perspective, they share a common belief that the system is in need of transformation.

\section{Change Agents and Organizations of Influence}

Several national organizations, such as the Institute for Healthcare Improvement (IHI) and the IOM, have become forces for change in American health care. Commercial interests, such as pharmaceutical companies, with their considerable market influence, may be considered organizations of influence and potential partners. Certain foundations, such as the Gates, Kellogg, and Robert Wood Johnson foundations, also exert influence through their funding and programming priorities. While some may debate whether medical schools and academic medical centers are change agents, they do have influence and must be addressed. In this regard, the Association of American Medical Colleges (AAMC) is another important potential partner. Family medicine should develop special relationships with these influential organizations through shared projects. For example, the task force's recom- 
mendation to develop and report on quality measures for each of the 6 IOM aims would make for a natural partnership for IHI, IOM, and family medicine.

\section{Health Plans}

The managed care movement of the 1990s showed the considerable influence that can be exerted by health plans. Jockeying for market niche, health plans have demonstrated variable commitment to and support of a primary care medical home model. Americans have not appreciated fully the potential harm of a fragmented and reductionistic approach to health care, nor have they realized fully the potential benefit of primary care. The improved outcomes, satisfaction, and efficiencies offered by a primary care model must be communicated more effectively to the American public and to health plans through better data and better performance.

\section{Employers and Labor Organizations}

The rising costs of health care are of concern to both employers and workers. Management and labor share a desire for better value and service for their health care investment. Their growing disquiet with the current health care system provides an opportunity for family medicine and primary care to form an alliance with employer and labor groups to respond to their concerns.

\section{Government Policy Makers}

Government funds nearly one half of all health care spending and is an important determinant of US health policy. The decisions of federal and state legislatures and agencies have an impact on health care through the health plans they administer (eg, Medicare, Medicaid, the Federal Employee Health Benefits Program, and the Department of Defense health care system), as well as through the direct services they provide through the Indian Health Service, the Veterans Administration health system, the National Health Service Corps, and public health hospitals, clinics, and nursing services. In addition, government funding through such agencies as the National Institutes of Health (NIH) shapes public health policy and opinion. Supportive government policies have great importance for primary care.

\section{Nongovernmental Policy Makers}

Numerous private organizations, such as the Accreditation Council for Continuing Medical Education (ACCME), the Accreditation Council for Graduate Medical Education (ACGME), the Joint Commission on Accreditation of Healthcare Organizations (JCAHO), and the Liaison Committee on Medical Education (LCME), shape health policy through their accreditation decisions. Family medicine should know and be known by these nongovernmental policy makers.

\section{Proposed Strategic Priorities (What)}

In establishing the strategic priorities for family medicines, the following should be the overriding principle: that health system change should be patient centered, relationship based, quality focused, and team oriented. While the entire enterprise of the Future of Family Medicine project has been to identify ways in which family medicine should create change, it is important to recommend change that will reflect patient values, strengthen the patient-physician relationship, assure the quality and competence of the care provided, and reinforce the commitment to working in the context of health care teams. Toward that end, this report identifies 6 priorities and discusses strategies for accomplishing those objectives:

1. Transforming the health care system through leadership

2. Accessing care through a personal medical home.

3. Proving and improving the quality of care provided through the medical home

4. Assuring health care coverage for everyone in a transformed health care system

5. Developing reimbursement models to sustain family medicine and primary care

6. Stimulating research to address important clinical care questions

\section{Specific Tactics (How)}

Specific tactics will depend ultimately on the major strategies or priorities decided by the Project Leadership Committee (PLC) of the FFM project and its parent organizations, and on the specific audiences (who) that are relevant for the strategy or priority under consideration. The leadership matrix lends itself to a structured approach for accomplishing specific priorities by addressing relevant audiences through focused recommendations or tactics. Given the 6 priorities addressed in this report and the 12 likely audiences identified above, there are at least 60 possible tactics. This report discusses only a few tactics and recommendations for illustrative purposes.

\section{Nature and Role of Leadership in Transforming Health Care}

Effective leadership is an essential ingredient that will determine, to a large extent, the success of family medicine in advocating for needed change in the health care system overall and in the specialty. In the context of this report, leadership can be defined as persuading others to act through a compelling vision, and taking risks to achieve that vision.

Speaking about the nature of leadership, singer and activist Marian Anderson once said, "Leadership should be born out of the understanding of the needs of those who would be affected by it." 6 Family physicians are the 
only physicians distributed across the United States in roughly the same proportion as the population. Family physicians care for all generations in all settings; they bridge personal and public health issues. Few health care professionals are better situated to understand the individual and collective health care needs of Americans than are family physicians. The ongoing relationships family physicians have with their patients, families, and communities enable them to understand those needs. It must be those needs that form the basis for creating a vision of the preferred future US health care system. While a compelling vision for the health care system has yet to gain widespread acceptance, this task force believes it should encompass the 6 IOM aims and should include measurable medical and service outcomes, patient values, and costs.

Much of the discussion about health care reform has centered on the financing of care. Equity and efficiency demand that every American should have adequate health care coverage. Yet, coverage is a necessary, but insufficient, element of an improved health care system. Equally important is a reordering of the organization and delivery of American health care. US health care is focused excessively on rescue medicine at the expense of preventive, primary, and restorative care. Noted historian Rosemary Stevens has written that American medicine "historically was geared to produce specialists for acute, interventionist, high-technology medical care, targeted to a focused problem area, rather than support of patients through long periods of disability and multiple conditions." ${ }^{17}$

Changing the financing and delivery of American health care will require a special kind of leadership. There are different types of leaders: status leaders, such as a president of a country, who influence through their position; service leaders, such as Mother Teresa, who motivate through their selfless efforts for others; charismatic leaders, such as the Rev. Martin Luther King, Jr, who inspire through force of personality; and transformational leaders, who lead by empowering others to achieve a shared and compelling vision. As Henry Miller described, "The only way in which any one can lead us is to restore to us the belief in our own guidance." ${ }^{18}$

Family physicians are status leaders in their communities and, to some extent, the nation. They also are service leaders, by the nature of their work. Some family physicians are charismatic leaders. In matters of health care reform, it is vital that family physicians become transformational leaders. By understanding the needs of those they serve, by helping to shape a compelling vision for a better system, and by working with the many individual Americans whose lives they touch, family physicians offer the best hope for transforming the US health care system. For individual Americans, the complexity, expense, and politics of US health care can appear daunting and immutable. As transformational leaders, family physicians can show the public a path to a better system. In the end, it will be the collective decisions of individual Americans that will transform American health care.

The transformational leadership called for in this effort must be completely, even brutally, honest. This honesty must extend to family medicine itself. Family physicians must point out that some of what physicians do is wasteful, ineffective, and even harmful. The discipline must identify its own flaws and improve its practices. Family medicine must embrace clear and valid performance measures for all health care professionals, including physicians, and must demand patient-centered accountability. The discipline also must advocate for a health care financing system that provides universal coverage and controls medical inflation. By engaging their patients, communities, and leaders in a dialogue about health care, family physicians can change the nature of the American health care debate. Encouraging patients to discuss the system's strengths and weaknesses, supporting their attempts to challenge substandard care and service, and advocating a patient-centered system, all reflect transformational leadership in action.

Advocacy in pursuit of a reordering of health care priorities and a shift in the traditional medical paradigm in the United States poses a risk for the discipline of family medicine. Having labored mightily to gain entry to the hallowed halls of medicine, family practice has determined that the structure needs major renovation. Challenging the status quo means that family physician leaders may risk the disapproval of their family medicine colleagues, other physicians, and those with a vested interest in the current system. The task force believes that now is the time and that family physicians are the leaders to step forward and take those risks. Nothing less than the health of the American people is at stake.

\section{Leadership in the Past: Lessons for the Future} Leadership is part of the heritage of family medicine. Past leadership successes by the discipline provide important lessons that can be instructive as family physicians begin advocating for needed changes.

Established in 1947, the American Academy of General Practice innovated a requirement that every member obtain 50 hours of continuing medical education (CME) each year. In 1969, the transition from general practice to the specialty of family practice set a new standard when the American Board of Family Practice $(\mathrm{ABFP})$ conditioned diplomate status on the successful completion of a board-certification examination (ie, there would be no grandfathering) and required that every diplomate must pass a recertification exami- 
nation no less than every 7 years. More than 3 decades later, some specialty boards have only begun to move toward these educational and testing standards. The American Academy of Family Physicians (AAFP), the successor to the AAGP, has embarked recently on a program to require that $\mathrm{CME}$ presenters reveal the source and quality of the evidence used when making practice recommendations. While laudable, these 3 innovations-annual CME requirements, board certification and recertification standards, and the evidence basis of CME-represent endeavors within the control of family medicine. The only audiences affected directly, and in need of persuading, were family physicians. A better test of family medicine's leadership will be its ability to influence those outside the discipline of family medicine.

An example of the influence of family medicine outside of the discipline can be found in the insinuation of family medicine into medical schools. Beginning in 1969 there were no departments or divisions of family medicine in medical schools; there are now such departments or divisions in 114 of the 125 allopathic medical schools. The story of this achievement suggests a leadership model for other family medicine initiatives.

First in public and then in private medical schools, family medicine used a multipronged approach to secure its place in academic medicine. Local efforts were combined with state and national resources to focus on each school. Practicing family physicians often donated their practices as they joined the faculty and helped start a new residency that served as the beachhead for family medicine at a school. State academy chapters lobbied their legislatures to secure funding for the nascent programs. Statewide, family physicians directed their referrals to schools that were supportive of family medicine. At the national level, resources such as the Residency Assistance Program were founded to start up and assure the quality of training programs. School visitations by national family physician leaders impressed on local medical school leaders the importance of family medicine at their institution. Schools without academic units of family medicine were targeted for special efforts. Using this multipronged strategy of local champions, statewide commitment, and national resources, the number of target medical schools without academic units of family medicine was cut by half from 22 in 1990 to 11 today. A similar level of success, using similar strategies, was achieved with the current requirement of a family medicine clerkship that exists in $85 \%$ of US allopathic medical schools.

The lessons of past leadership success include the importance of identifying a shared priority across the discipline of family medicine and combining targeted resources and coordinated efforts at multiple levels.
Thus far, family medicine has concentrated on initiatives that are focused primarily inward (eg, CME, board certification, academic units), the challenge will be to achieve similar unity and momentum around issues that are focused outward (eg., health system reform).

Harold Geneen, who transformed International Telephone \& Telegraph into a worldwide business superpower during the 1960s, once said, "Leadership cannot really be taught. It can only be learned." ${ }^{\prime 9}$ Leaders who changed the fundamental direction of society come readily to mind in such areas as achieving selfgovernance through civil disobedience (eg, Mahatma Gandhi) or reengineering for quality (eg, Jack Welch). Such change leaders have not been as identifiable in health care generally or primary care specifically.

Even if leadership cannot be taught, it can and must be recognized, nurtured, and supported. Investment of resources and cultivation of talent will be needed for such leaders to emerge. This task force believes it is vitally important to groom leaders within family medicine who will change the health care landscape, as well as to create venues where policy makers and influence leaders can look beyond their usual constituencies and horizons to a comprehensive view of health care.

\section{Identification of Key Policy Initiatives and Implementation Strategies}

The FFM project has provided an important impetus for the identification of key priorities across the discipline. Ultimately, however, for the FFM project to be deemed a success, implementation steps will need to be identified and prioritized. This effort should involve family physicians and their organizations, as well as foundations, industry, and other potential funders.

Many believe that America's obsession with hightechnology acute care medicine, at the expense of preventive and primary care, is due in part to the loss of the voice of primary care amid the cacophony of media hype and industry advertising that show only the promise, and rarely the peril, of organ- and diseasecentered medicine vs relationship-centered medicine. The growth of complementary and alternative medical practices is partially the result of a failure of mainstream medicine to address adequately the many other important aspects of health (eg, prevention, nutrition, pain management, end-of-life care). The various primary care disciplines have all been involved in recent efforts aimed at self-reflection and redirection. To bring the health care system into better balance, however, the leaders of primary care must develop a stronger and more unified voice. Primary care is poised to reassert its primacy in health care. Convening a summit of primary care leaders will be a crucial first step toward a stronger and more unified voice. 
Family Medicine and Primary Care Leadership Center Even after common ground and mutual priorities are established, there will remain a need for continuing collaboration and advocacy across family medicine and the other primary care disciplines. A leadership center for family medicine and primary care is needed to provide a focal point for cross-disciplinary research on effective leadership strategies, to coordinate leadership development and advocacy efforts, and to cultivate resources for leadership programs and research.

Promoting Family Medicine Leadership

Strategies will need to be developed to promote family physicians and other primary care advocates as leaders in their communities, in government, and in other influential groups, particularly the AMA, AAMC, ACCME, ACGME, IHI, IOM, JCAHO, LCME, NIH, and National Quality Forum (NQF). Such strategies should include the identification of possible positions and candidates for those positions, the active promotion of those candidates by allies in target organizations and through campaigns for their selection, and the creation of networks of successful candidates to identify, mentor, and place additional primary care advocates.

\section{Blue-Ribbon Panel of Key Stakeholders}

Traditional efforts to create change in health care typically have involved large groups of putative experts or politically derived representatives and have resulted in proclamations that ultimately had little impact on the experience of health care in America. Existing entities, such as the IOM, the NIH, and the NQF, offer important perspectives on health care, but they often function in isolation or have agendas that are too narrow to effect meaningful change. Family medicine should advocate for the creation of a blue-ribbon panel of key stakeholders from advocacy groups, business, government, health care professionals, health-related industries, health plans, and labor. The panel should be charged with addressing comprehensive health system reform and articulating a compelling vision for health care in America.

\section{PRIORITY 2: A PERSONAL MEDICAL HOME FOR EVERY AMERICAN}

\section{Concept of a Personal Medical Home}

The FFM research found that only about $15 \%$ of Americans want to go it alone in health care; most prefer an ongoing relationship with a personal physician. ${ }^{5}$ This task force believes that the concept of a personal medical home will have considerable appeal for Americans.

Max DePree, who as chief executive officer of Her- man Miller, Inc, increased sales dramatically through his worker-friendly management style, wrote eloquently in Leadership Is an Art ${ }^{10}$ of the importance of leaders demonstrating their commitment through "covenantal relationships." This task force believes that an explicit commitment to a health care covenant will enhance the standing of family physicians as health care leaders.

Fitzhugh Mullan, MD, former Assistant Surgeon General of the US Public Health Service, predicts in Big Doctoring in America" that "Patients faced with quantities of data and multiple therapeutic choices will value clinicians who can help them weigh options and choose courses of action." The medical home, as proposed in this report, can serve as the focal point for an individual's health care, providing care that is accessible, accountable, comprehensive, integrated, and patient centered.

\section{Key Elements of the Personal Medical Home Concept}

Accessible-services that are accessible financially (affordable, all payers accepted), geographically (near home or work), and temporally (available 24 hours a day, 7 days a week)

Accountable-provides and reports service that meets quality standards

Comprehensive - offers a wide range of services, including basic health care services such as health education and promotion services; preventive services; evaluation and management of the undifferentiated complaint; care of both acute and chronic conditions; end-of-life care; and referral to other clinicians as appropriate

Integrated-serves as the entry point for health care, develops a care plan for each individual ${ }_{i}$ maintains a comprehensive and confidential health record for each individual, and integrates care across all professionals (eg, consultants) and all settings (eg, home, hospital, extended care facility, office)

Patient centered-provides services that are empathic, respectful, and culturally effective

Americans value choice. At the same time, studies show that care organized around a primary care relationship results in better outcomes at lower cost with higher satisfaction. Incentives can be developed that will allow Americans to choose the kind of health care they want, but at a price that reflects the effectiveness and efficiency of the model they choose. Individuals should be able to choose or change their medical home through an easy and well-defined process. Maintaining a continuous relationship with an identified personal medical home should be supported. A standard health care covenant should describe explicitly the mutual expectations of the individual and the medical home. 


\section{Implementing the Personal Medical Home Concept}

Implementation of the medical home concept will depend on changes in medical education and health care funding and organization, so that trainees and clinicians will be attracted in sufficient numbers to primary care to meet the workforce needs associated with this recommendation. In addition, efforts to enhance health literacy among patients will need to be initiated, including an information campaign on the benefits of having a personal medical home, and standards for an electronic health record will need to be developed that promote the use of a personal medical home and encourage research in practice improvement.

Several initiatives are underway to encourage the use of an electronic health record. Notable examples include the systems developed by the Veterans Administration and the Department of Defense. The AAFP has worked with a number of private companies to make inexpensive products available. Unfortunately, few if any EHR systems allow for the easy integration of information from diverse sources (hospital, office, long-term care facility, etc). While HIPAA (Health Insurance Portability and Accountability Act) regulations provide some guidance, they do not address the standards issue in a manner that will meet the electronic information needs of the personal medical home.

It is essential that EHR systems promote, rather than impede, the concept of a personal medical home. Whether the system is patient-controlled (eg, smart cards), Web-based, or medical-home-based, high priority must be given to assuring that information from multiple, diverse sources can be pulled together into a single system to support the comprehensive information needs on which primary care practices depend. Similarly, EHR systems must permit the collection, analysis, and reporting of the clinical decisions, and their outcomes, that primary care clinicians must make every day. Key audiences for this recommendation includes family physicians and other clinicians, and their organizations; other physicians and their organizations; organizations of influence; health plans and other payers; and government policy makers.

\section{PRIORITY 3: QUALITY MEASURES TO IMPROVE PERFORMANCE AND SERVICE}

Quality has proved to be a challenging notion in health care. While it is universally desired, and most people recognize it when they experience it, there has been limited resolve to develop agreement on, funding of, and measures for quality. Quality includes measures of outcomes that patients care about (death, discomfort, disability), as well as customer service and costs. Qual- ity measurement, driven in part by the patient safety movement, is gaining momentum and will be an enduring challenge and opportunity for health care. As a first step toward accomplishing priority 3 , family medicine should develop and begin reporting regularly for all family physicians their performance on at least 1 measure for each of the 6 IOM aims of high-quality health care: safe, timely, effective, equitable, patient-centered, and efficient.

Many measures of quality (eg, those developed by JCAHO, NCQA) have focused at the level of health care institutions or health plans, rather than at the level of the practicing clinician. The measures are often best suited to tracking the general health services of populations, not necessarily improving individual clinical care decisions. Moreover, many measurement systems represent extra practice costs and are so complex as to be of questionable utility to individual clinicians or patients. Adopting 6 measures of quality, 6 for each of the IOM aims, might be challenged as overly simplistic. This task force believes, however, that at least one practical and meaningful measure could be identified for each aim. A nationwide system reporting on those 6 measures would position family physicians as innovative advocates for quality and transparency. Target audiences would include every audience: patients would be asked for their preferences for possible measures and ways to report them, family physicians would need to embrace the concept and incorporate the measures into their practices ${ }_{i}$ measures must be meaningful to other physicians, health care professionals, and their organizations; and support from organizations of influence, health plans, and government would be helpful in establishing the validity, credibility, and acceptability of the measures.

Once the measures have been identified, academic family physicians would be essential participants for this recommendation. With time, academic organizations such as the Residency Review Committee for family practice would be expected to tie residency program accreditation to acceptable performance by residency graduates. Family medicine residencies would be expected to track and report regularly the performance of their graduates over time against the 6 measures and modify their training programs to improve the performance of their graduates.

\section{PRIORITY 4: BASIC HEALTH CARE COVERAGE FOR EVERY AMERICAN}

Reform of the funding of American health care is an essential part of the healing of the ailing system. The lack of health care coverage for all Americans results in inequities and inefficiencies that can no longer be sus- 
tained and should no longer be tolerated. It is essential for every American to have health care coverage that assures adequate funding of basic health care services and protection against extraordinary health care costs. Once the goal of health care coverage for everyone is accomplished, tools will need to be developed to help patients make informed decisions about a personal medical home and health care coverage.

\section{PRIORITY 5: REIMBURSEMENT MODELS TO SUSTAIN FAMILY MEDICINE AND PRIMARY CARE}

The current reimbursement system for primary care practices is not sustainable. Practice resources are insufficient in the current system to accomplish many of the tasks essential for an improved and transformed health care system (eg, every American able to choose a medical home, an electronic health record, reporting on performance of the 6 quality aims). Specific recommendations regarding reimbursement and financial models for family practices are being developed by a newly formed FFM task force, which is expected to report its findings and recommendations in 2004.

\section{PRIORITY 6: RESEARCH THAT SUPPORTS PRIMARY CARE CLINICAL DECISION MAKING}

Investigator-initiated basic science has yielded tremendous knowledge about basic concepts. When clinical research has been done, it has usually been conducted in academic medical centers, which comprise a very small and atypical representation of American patients and practice. Thus, federally funded research has had an uneven and inadequate impact on clinical practice. Better balance in research priorities and funding is needed to assure that clinicians have answers to the questions they confront in daily practice. Research is an essential component of quality and continuous improvement and should be woven into every practice. Government funders, foundations, health plans, and others should promote research by and for family physicians as a longterm investment to enhance patient care and health system improvement. The AAFP has shown considerable leadership through its research initiative and the nearly $\$ 8$ million that has been invested during the past 5 years to stimulate research in the discipline.

It is time for the research needs of family medicine and primary care to be placed on an equal footing with the rest of medicine. The tremendous disparity in federal funding for primary care research compared with research funding for the rest of medicine has meant that important questions raised by the clinicians who provide most of the medical care go unexamined and unanswered. An institute at the National Institutes of Health should be established to foster, coordinate, and fund research in family medicine and primary care. A communications network for primary care clinicians should be created to enable them to share data, answer questions, and solve problems that are broad based and relevant. Practice-based research networks and sentinel practice systems are examples of such networks. Another strategy to accelerate the research capacity of primary care could be a Web-based forum for peer review of research proposals in development by family physicians. Target audiences for this recommendation include family physicians and other primary care clinicians, medical schools and academic medical centers, and government policy makers.

Funding drives research priorities. Funding should therefore be provided to encourage academic and other institutions to pursue research on the value of a personal medical home and how the concept can be improved. This recommendation would target research funders and academic and research institutions, as well as investigators.

\section{SUMMARY}

Family medicine has and will continue to have an important leadership role in health system change. It has been most successful when it has been able to identify a high-priority goal by achieving consensus across the discipline, focus and coordinate local and national resources, and employ a multipronged approach in addressing the priority. The leadership matrix presented in this report can provide a useful structuring tool to identify, understand, and coordinate change efforts more effectively. Strategic alliances with primary care groups and others will be critical to the success of change initiatives.

\section{RECOMMENDATIONS}

\section{Priority 1: Family Medicine Leadership}

Recommendation 1.1. That the discipline of family medicine target by 2004 a few major policy initiatives and employ a multipronged approach for their implementation.

Recommendation 1.2. That a summit of family medicine and primary care leaders be convened in 2004 to identify major policy initiatives.

Recommendation 1.3. That a leadership center for family medicine and primary care be established by 2005 .

Recommendation 1.4. That explicit strategies be developed by 2005 to promote family physicians and other primary care advocates as leaders in their 
communities, in government, and in other influential groups.

Recommendation $\mathbf{1 . 5}$. That family medicine advocate for the creation of a blue-ribbon panel of key stakeholders by 2006 to address comprehensively the American health care system and articulate a compelling vision for its transformation.

\section{Priority 2: Personal Medical Home}

Recommendation 2.1. That steps be taken to ensure that every American will have the opportunity to choose an identified personal medical home by 2010 .

Recommendation 2.2. That efforts be initiated to enhance health literacy among patients, including an information campaign beginning in 2005 on the value of a personal medical home

Recommendation 2.3. That standards for an electronic health record be developed by 2005 , which promote the use of a personal medical home and encourage research in practice improvement.

\section{Priority 3: Quality}

Recommendation 3.1. That family medicine develop by 2005 and begin by 2006 regular reporting for all family physicians their performance on at least 1 measure for each of the 6 IOM aims of high-quality health care: safe, timely, effective, equitable, patient-centered, and efficient.

Recommendation 3.2. That family medicine residencies by 2006 track and report regularly the performance of their graduates over time against the 6 IOM quality measures and modify their training programs to improve the performance of their graduates.

\section{Priority 4: Health Care Coverage for All}

Recommendation 4.1. That steps be taken to ensure every American has health care coverage by 2009 which assures adequate funding of basic health care services and protection against extraordinary health care costs.

Recommendation 4.2. That tools be developed by 2008 to help patients make informed decisions about a personal medical home and health care coverage.

\section{Priority 5: Reimbursement}

Recommendation 5.1. Reimbursement models will be developed by 2006 that sustain and promote primary care practices so that they may thrive and serve as personal medical homes.

\section{Priority 6: Research}

Recommendation 6.1. That a National Institute for Family Medicine and Primary Care be established by 2009 to foster, coordinate, and fund research in family medicine and primary care.
Recommendation 6.2. That funding be provided by 2005 to encourage academic and other institutions to pursue research on the value of a personal medical home.

To read or post commentaries in response to this article, see it online at http://www.annfammed.org/cgi/content/full/2/suppl_1/S88.

Key words: Leadership; family medicine; public policy; politics; delivery of health care; reimbursement; insurance, health; health system agencies

Funding Support: The Future of Family Medicine Project is supported by the following family medicine organizations: American Academy of Family Physicians (AAFP), American Academy of Family Physicians Foundation (AAFPF), American Board of Family Practice (ABFP), Association of Departments of Family Medicine (ADFM), Association of Family Practice Residency Directors (AFPRD), North American Primary Care Research Group (NAPCRG), and Society of Teachers of Family Medicine (STFM). Major support has been contributed by Eli Lilly Foundation; Pharmacia, Pharmacia Foundation; Pfizer, Pfizer Foundation; and the Robert Wood Johnson Foundation. In addition, generous support has been obtained from the Health Resources and Services Administration, Schering-Plough Corporation, and Wyeth Pharmaceuticals.

Members of Task Force 5: Richard G. Roberts, MD, JD, Chair, Madison, Wisc; Pam S. Snape, MD, Vice Chair, Greenville, SC; Beverly E. Aist, MD, San Antonio Tex; Errol Alden, MD, Elk Grove Village, IIl; Maggie Blackburn, MD, Stamford, NY; Paul C. Brucker, MD, Philadelphia, Pa; Neil Stephen Calman, MD, New York, NY; Nancy Dickey, MD, Bryan, Tex; Ann C. Jobe, MD, MSN, Macon, Ga; Jean K. Johnson, RN-C, PhD, Washington, DC; Walter McDonald, MD, Phoenixville, Pa; David Satcher, MD, PhD, Atlanta, Ga; Kevin Burke, Staff Executive, Washington, DC.

Acknowledgments: The task force benefited greatly from the input of many people, including all the members of the Future of Family Medicine Project Leadership Committee, the Family Medicine Working Party, FFM project and task force staff, members of the other FFM task forces, and particularly the group of external reviewers listed below.

Project Leadership Committee: James C. Martin, MD, Project Leadership Committee Chair; Robert F. Avant, MD; Marjorie A. Bowman, MD, MPA; John R. Bucholtz, DO; John C. Dickinson, MD; Kenneth L. Evans, MD; Larry A. Green, MD; Douglas E. Henley, MD; Warren A. Jones, MD; Samuel C. Matheny, MD, MPH; Janice E. Nevin, MD, MPH; Sandra L. Panther, CFRE; James C. Puffer, MD; Richard G. Roberts, MD, JD; Denise V. Rodgers, MD; Roger A. Sherwood, CAE; Kurt C. Stange, MD, PhD; Cynthia W. Weber, MA.

Future of Family Medicine Research Advisory Committee: John R. Bucholtz, DO; John C. Dickinson, MD; Larry A. Green, MD; Warren A. Jones, MD; James C. Martin, MD; Richard G. Roberts, MD, JD; Kurt C. Stange, MD, PhD.

Future of Family Medicine Project Staff: Norman B. Kahn, Jr, MD, FFM Staff Executive; Sarah Thomas, Assistant Staff Executive; Marilyn A. McMillen, MBA, Project Manager; Dorothy Young, FFM Administrative Assistant; Nina Carnoali, FFM Staff Assistant; Ruth Coram, FFM Staff Assistant.

Reactor Panel: James Bentley; Judy Chamberlain, MD; Stephen C. Crane, PhD, MPH; Bob Crittenden, MD; Carol C. Diamond, MD, MPH; Michael Fine, MD; John Geyman, MD; Charles Inlander; Virgilio Licona, MD; John Little; Alma Littles, MD; Mike Magee, MD; Fitzhugh Mullan, MD; Lee Newcomer, MD; Ed O’Neil; Mike Rosenthal, MD; Thomas Rosenthal, MD; Robert Schiller; Rosemary A. Stevens, MPH; Linda J. Stierle, MSN, RN, CNAA; Sheila Tate; Greg Thomas; Bruce Soloway, MD. 


\section{References}

1. Shaw GB. The Doctor's Dilemma. London: Penguin; 2002.

2. Graham R, Roberts RG, Ostergaard DJ, Kahn NB, Pugno PA, Green LA. Family practice in the United States: a status report. JAMA. 2002;288:1097-2001.

3. Institute of Medicine. Committee for Quality in Health Care in America. Crossing the Quality Chasm: A New Health System for the 21st Century. Washington, DC: National Academy Press; 2001.

4. Starfield B. Primary Care: Concept, Evaluation and Policy. New York, NY: Oxford University Press; 1992.

5. Family Medicine Working Party and Academic Family Medicine Organizations. Future of Family Medicine Web site. Available at: http://futurefamilymed.org.
6. Anderson M. New York Times. July 22, 1951.

7. Stevens R. American Medicine and the Public Interest. Berkeley: University of California Press; 1998:xxiii.

8. Miller H. The Wisdom of the Heart. New York, NY: WW Norton $\varepsilon$ Co; 1960.

9. Geneen H. Managing. New York, NY: Doubleday; 1984.

10. DePree M. Leadership is an Art. New York, NY: Doubleday; 1989.

11. Mullan F, Milbank SL, Moses J. Big Doctoring in America. Berkeley: University of California Press; 2002:227. 